\title{
Ensino/aprendizagem de língua portuguesa na escola: explorando letramentos
}

\section{Portuguese language teaching/learning in school: exploring literacies}

\author{
Hélvio Frank de Oliveira* \\ *Universidade Estadual de Goiás (UEG), Itapuranga, Goiás / Brasil \\ helviofrank@hotmail.com

\section{Tatiane Dutra de Godoi Arriel**} \\ **Secretaria de Estado de Educação, Cultura e Esporte - Goiás, Morro Agudo de \\ Goiás, Goiás, Brasil \\ tatianedga@gmail.com
}

\begin{abstract}
RESUMO: Neste artigo, objetiva-se problematizar práticas escolares envolvendo língua/linguagem a partir de uma experiência localizada de ensino de língua portuguesa. A pesquisa-ação foi orientada pela pluralidade de letramentos, conduzida pela professora pesquisadora e seus estudantes do segundo ano de ensino médio de uma escola pública de Goiás. O material empírico de interpretação constitui-se de questionários discentes, de notas de campo e diário reflexivo da professora pesquisadora, e de entrevistas semiestruturadas com os estudantes. Os resultados apontam para a relevância de projetos que subvertam didáticas enrijecidas de ensino/aprendizagem de língua portuguesa, especialmente aquelas práticas voltadas exclusivamente ao letramento da letra.
\end{abstract}

PALAVRAS-CHAVE: letramentos; aula de língua portuguesa; educação linguística crítica.

\begin{abstract}
In this article we aim to problematize school practices involving language based on a localized experience of Portuguese language teaching. The action research was guided by the plurality of literacies, conducted by the teacher-researcher and her students of the second year of high school in a public school in Goiás, Brazil. The empirical material of interpretation consists of student questionnaires, teacher-researcher's field notes and reflective journals, and semi-structured interviews with students. The results point to the relevance of projects that subvert traditional didactic aspects in Portuguese language teaching/learning, especially those practices focused exclusively on formal literacy.
\end{abstract}

KEYWORDS: literacies; Portuguese class; critical language education. 


\section{Introdução}

Diante da heterogeneidade que abriga os estudos de letramento no contexto brasileiro, uma providência pedagogicamente necessária consiste na ampliação do conceito e de sua abrangência no campo social. No contexto escolar, embora frentes de estudos, após a década de 1980, buscaram alertar para a relevância de outros letramentos, leitura e escrita continuam como habilidades técnicas que se fundamentam apenas no modelo único e dominante de letramento: o formal (TERRA, 2013). Em meio a tantas evoluções do pensamento linguístico, ainda hoje professores de língua portuguesa tendem a homogeneizar e a padronizar práticas, saberes, falares etc., preconizados por um modelo ocidental de letramento moldado em aspectos formais, brancos, masculinos e escolarizados de comunicação (MASCIA, 2009). Com isso, continuam a desconsiderar a órbita social e híbrida dos usos e formas de manifestação da linguagem.

Com a pretensão de tornar a ideia de letramento escolar menos “ilusória” (HAMILTON; BARTON, 1999), o objetivo principal deste texto é produzir reflexões linguístico-pedagógicas acerca de uma experiência localizada de ensino de língua portuguesa envolvendo professora e estudantes de uma turma de segundo ano do ensino médio noturno de uma escola pública no interior do estado de Goiás. Sustentamos nossas interpretações no princípio de existência humana (FREIRE, 1987), em que existir ultrapassa viver, incorpora criticidade, envolve o sentido de estar no mundo e com o mundo. Trazendo esse pensamento para o contexto teórico de análise, invoca-nos problematizar a conexão horizontal entre o letramento que a escola, por intermédio do professor de língua portuguesa, promove e os letramentos que alunos trazem consigo para a sala de aula.

\section{A contextualização da proposta}

A construção desta pesquisa envolveu procedimentos metodológicos qualitativos e interpretativistas (DENZIN; LINCOLN, 2006; FLICK, 2009) voltados à condição linguística, social e localizada dos participantes envolvidos (GEE, 2015). A experiência situada se efetivou sob a perspectiva de pesquisa-ação (THIOLLENT, 2005) realizada numa escola pública da rede estadual de ensino em Goiás, num município que possui aproximadamente 2,5 mil habitantes, localizado a 200 quilômetros da capital. O material empírico, produzido após o diagnóstico da falta de interesse discente nas 
aulas assistidas e o desejo por novidades em sala de aula, foi gerado em uma turma de segundo ano do ensino médio noturno, composta de 18 estudantes, sendo 10 pessoas declaradas do sexo masculino e 8 do sexo feminino, com média de idade entre 15 e 18 anos.

A professora pesquisadora (doravante PP), que à época estava afastada da escola em que trabalhava, para fins de qualificação profissional, foi convidada pelos colegas para ministrar uma oficina de língua portuguesa à turma, tendo em vista a dificuldade dos alunos em ler e escrever, bem como o baixo rendimento discente em avaliações oficiais. A proposta se materializou na intersecção entre gêneros discursivos e letramentos. O Quadro 1 apresenta um breve perfil dos estudantes, obtido com o auxílio do questionário inicial (QI) aplicado aos alunos.

QUADRO 1 - Perfil dos participantes da pesquisa

\begin{tabular}{|c|c|c|c|c|}
\hline $\begin{array}{c}\text { Pseudônimo }^{1} \\
\text { do } \\
\text { participante }\end{array}$ & Idade & Sexo & Ocupação & Atividade preferida nas horas vagas \\
\hline Ana Flor & 15 & $\mathrm{~F}$ & Estudante & Assistir à TV, dormir. \\
\hline Ana Victória & 17 & $\mathrm{~F}$ & Estudante & Acessar Whatsapp, Facebook, Messenger. \\
\hline Cachoera & 16 & M & Serviço agropecuário & Andar de moto e jogar no celular. \\
\hline Capricho & 15 & $\mathrm{~F}$ & Estudante & Acessar Whatsapp. \\
\hline Chefe & 17 & M & Serviço agropecuário & Andar de moto com os amigos. \\
\hline Diamante & 16 & $\mathrm{~F}$ & Estudante & Brincar com a irmã, se cuidar e andar de moto. \\
\hline Estrella & 15 & $\mathrm{~F}$ & Doméstica & Sair com os amigos, mexer no celular. \\
\hline Goku & 15 & M & Serviço braçal. & Dormir e andar à toa. \\
\hline José & 18 & M & Serviços rurais & Andar de moto e passear nas ruas. \\
\hline Maresia & 16 & M & Serviços rurais & Correr de moto. \\
\hline Margarida & 16 & $\mathrm{~F}$ & Estudante & $\begin{array}{l}\text { Sair com os amigos, mexer no celular, visitar os } \\
\text { avós, andar de carro. }\end{array}$ \\
\hline Mocher & 15 & M & Estudante & Jogar bola e sair com os amigos. \\
\hline Omikami & 17 & M & Entregador em loja & Estar na fazenda e ajudar o pai a lidar com gado. \\
\hline Pedro & 16 & M & Estudante & Mexer no celular. \\
\hline Red Bull & 16 & M & Serviços rurais & Andar de moto. \\
\hline Tici & 18 & $\mathrm{~F}$ & Estudante & Acessar o Whatsapp e assistir à TV. \\
\hline Violeta & 15 & $\mathrm{~F}$ & Estudante & Andar de bicicleta e cavalgar. \\
\hline Zika & 16 & M & Serviço agropecuário & Dormir. \\
\hline
\end{tabular}

${ }^{1}$ Por questões éticas, os participantes escolheram os próprios pseudônimos. 
As três fases da pesquisa-ação consolidaram-se 1) no levantamento das práticas vivenciadas nas aulas de língua portuguesa; 2) na elaboração da proposta de intervenção e produção de materiais; e 3) na ação desenvolvida. Todas foram implementadas pela PP deste trabalho, que assumiu as aulas de língua portuguesa na turma, seguiu o calendário oficial da instituição e os conteúdos programáticos estabelecidos no Currículo de Referência, ${ }^{2}$ no primeiro semestre de 2016. Foram ministradas 17 aulas de língua portuguesa, planejadas previamente a partir de uma sequência didática, ${ }^{3}$ e envolveram, na ação realizada, textos multimodais com múltiplas semioses conectados às práticas socioculturais dos participantes, bem como ao material de apoio do Programa Escrevendo o Futuro. ${ }^{4}$

O material empírico deste estudo engloba o questionário inicial (QI) respondido pelos estudantes no início da pesquisa, as notas de campo (NC) produzidas pela $\mathrm{PP}$ a partir de conversas informais com a professora regente e alunos, da participação na reunião do conselho de classe e das observações de aulas durante a estada em campo, o diário reflexivo (DR) escrito pela PP

\footnotetext{
${ }^{2} \mathrm{O}$ Currículo de Referência é uma diretriz produzida no estado de Goiás, elaborada em torno de eixos temáticos, que dizem respeito ao uso da linguagem por meio das práticas de oralidade, de leitura, de escrita e de reflexão sobre a língua e a linguagem. Tais eixos são relacionados às expectativas de aprendizagem e aos conteúdos, explorados a partir dos gêneros discursivos, para cada bimestre e ano (GOIÁs, 2012). O documento infere a necessidade de se escolherem textos locais e situados, específicos do gênero selecionado para o ensino. Os conteúdos e expectativas referentes ao $2^{\circ}$ bimestre, período da pesquisa, contemplaram o gênero "artigos de opinião", uma vez que "Contos literários" já haviam sido trabalhados pela docente da turma (GOIÁS, 2012, p. 62).

${ }^{3}$ Com base em Dolz, Noverraz e Schneuwly (2004, p. 82), definimos sequências didáticas como "um conjunto de atividades escolares organizadas, de maneira sistemática, em torno de um gênero textual oral ou escrito", e incluímos, aqui, o visual. De acordo com os autores, elas servem para "dar acesso aos estudantes a práticas de linguagem novas" (p. 83). No contexto aplicado, o propósito da sequência didática foi o de auxiliar os estudantes a dominar gêneros textuais, apropriando modalidades linguísticas de acordo com a situação de comunicação.

${ }^{4}$ O Programa Escrevendo o Futuro é uma iniciativa da Fundação Itaú Social, coordenado pelo Centro e Estudos e Pesquisas em Educação, Cultura e Ação Comunitária (Cenpec), tem como objetivo contribuir para melhoria da leitura e escrita nas escolas públicas do Brasil. Foi criado em 2002 e, em 2008, transformou-se em política pública, em parceria com o Ministério da Educação na realização da Olimpíada de Língua Portuguesa. Disponível em: $<$ https://bit.ly/2sRzMEf $>$. Acesso em: 14 jul. 2017.
} 
após cada aula ministrada, e as entrevistas semiestruturadas produzidas com sete estudantes após a intervenção, gravadas em áudio e posteriormente transcritas ${ }^{5}$ com a utilização dos seguintes símbolos:

\begin{tabular}{|c|l|}
\hline Itálico & Variação linguística na fala \\
\hline Negrito & Ênfase na fala \\
\hline$\ldots$ & Qualquer interrupção \\
\hline[] & Acréscimo de trechos de contextualização \\
\hline$[\ldots]$ & Supressão de trechos \\
\hline 0 & Trecho inaudível \\
\hline
\end{tabular}

Para a interpretação do material empírico, utilizamos o critério de recorrência temática em diálogo com o conceito de letramentos como práticas sociais (STREET, 2014) sob uma vertente transdisciplinar, pluralizada, complexa e situada, na tentativa de romper com paradigmas modernos de orientação para o ensino de língua portuguesa. Com isso, acenamos para epistemologias emergentes e contra-hegemônicas de percepção do que seja aprender tal língua, a partir de duas grandes discussões ${ }^{6}$ propostas: 1) os letramentos situados, que envolvem a configuração da disciplina de língua portuguesa na educação básica e os estudos de letramento(s) na contemporaneidade e 2) os letramentos em (trans) formação,que se constituem a partir do objetivo da proposta de intervenção em campo, a saber, da intersecção entre letramentos, gêneros discursivos e expectativas discentes.

\footnotetext{
${ }^{5}$ Nos excertos que contêm fragmentos narrativos e discursivos dos participantes, fizemos alguns ajustes linguísticos após transcrição, sem prejuízo ao conteúdo do relato. Neles, também disponibilizamos as iniciais do instrumento utilizado e, quando necessário, o pseudônimo do participante.

${ }^{6}$ Este texto subverte o modelo hegemônico de pesquisa pautado na fragmentação e divisão entre fundamentação teórica e análise de dados ao diluir as discussões de pesquisadores com as teorizações realizadas pelos participantes. Tal ação se justifica pela compreensão de que teoria e prática se mesclam, ou pelo menos deveriam se misturar, à dimensão humana de construção de conhecimentos, de forma concomitante e não sucessiva.
} 


\subsection{O ensino/aprendizagem de língua portuguesa institucionalizado}

Localizar as práticas de ensino/aprendizagem, tal qual pretendemos neste estudo, significa caracterizar toda a problemática que envolve o contexto de investigação. Significa, para além disso, compreender, na perspectiva de Gee (2015), que, para aprender com profundidade, é preciso mais que textos e palavras: é preciso levar em consideração experiências. Com o auxílio do QI, constatamos o desafio da condição noturna que, conforme estudos do MEC, é caracterizada pela frequência do aluno trabalhador diurno, configurando-se como única opção na escola pesquisada. Os participantes apresentam o seguinte perfil:

QUADRO 2 - Situação socioeconômica dos participantes

\begin{tabular}{|c|c|c|c|c|c|}
\hline Participantes & Trabalha? & $\begin{array}{c}\text { Renda mensal } \\
\text { da família } \\
\text { (em salários) }\end{array}$ & $\begin{array}{c}\text { Carga horária } \\
\text { diária de } \\
\text { trabalho }\end{array}$ & $\begin{array}{l}\text { Número de } \\
\text { Moradores } \\
\text { na casa }\end{array}$ & Ocupações diárias \\
\hline Ana Flor & Não & Até 1 & - & 4 & $\begin{array}{l}\text { Ajudar em casa, assistir à TV, } \\
\text { mexer no celular. }\end{array}$ \\
\hline Ana Victória & Não & $3 \mathrm{a} 4$ & - & 5 & $\begin{array}{l}\text { Arrumar casa, fazer atividades } \\
\text { escolares, assistir à TV. }\end{array}$ \\
\hline Cachoera & Sim & 1 a 2 & 3 & 4 & $\begin{array}{l}\text { Tirar leite de vaca na fazenda, } \\
\text { ajudar o pai. }\end{array}$ \\
\hline Capricho & Não & Até 1 & - & $+\operatorname{de} 6$ & Arrumar casa. \\
\hline Chefe & $\operatorname{Sim}$ & 4 & $+\mathrm{ou}-10$ & 5 & Mexer com gado, assistir à TV \\
\hline Diamante & Não & 1 a 2 & - & 4 & $\begin{array}{l}\text { Arrumar casa, assistir à TV, } \\
\text { conversar com amigos. }\end{array}$ \\
\hline Estrella & Sim & $1 \mathrm{a} 2$ & 4 & 4 & $\begin{array}{l}\text { Trabalho doméstico, assistir à } \\
\text { TV, mexer no computador. }\end{array}$ \\
\hline Goken & $\operatorname{Sim}$ & 4 & 8 a 9 & 5 & $\begin{array}{l}\text { Trabalhar por dia, serviço } \\
\text { braçal. }\end{array}$ \\
\hline José & $\operatorname{Sim}$ & Até 1 & 10 & 4 & Trabalhar na fazenda. \\
\hline Maresia & $\operatorname{Sim}$ & $3 \mathrm{a} 4$ & 10 & 4 & $\begin{array}{l}\text { Tirar leite e trabalhar na } \\
\text { fazenda. }\end{array}$ \\
\hline Margarida & Não & 3 a 4 & - & 3 & Assistir à TV, arrumar casa. \\
\hline Mocher & Não & $1 \mathrm{a} 2$ & - & 4 & $\begin{array}{l}\text { Ajudar a mãe e o pai, assistir } \\
\text { à TV. }\end{array}$ \\
\hline Omikami & $\operatorname{Sim}$ & $1 \mathrm{a} 2$ & 10 & 4 & $\begin{array}{l}\text { Trabalha em loja de materiais } \\
\text { de construção. }\end{array}$ \\
\hline Pedro & Não & $1 \mathrm{a} 2$ & - & 3 & Mexer no celular e dormir. \\
\hline Red Bull & $\operatorname{Sim}$ & 3 a 4 & 10 & 3 & $\begin{array}{l}\text { Trabalhar na fazenda e assistir } \\
\text { à TV. }\end{array}$ \\
\hline
\end{tabular}




\begin{tabular}{|l|c|c|c|c|l|}
\hline Tici & Não & até 1 & - & 4 & Arrumar casa e assistir à TV. \\
\hline Violeta & Não & 1 a 2 & - & 6 & $\begin{array}{l}\text { Ajudar em casa, assistir à TV, } \\
\text { dormir. }\end{array}$ \\
\hline Zika & Sim & 1 a 2 & + ou-10 & 2 & $\begin{array}{l}\text { Tirar leite de vaca, entre outros } \\
\text { serviços rurais. }\end{array}$ \\
\hline
\end{tabular}

Uma parcela significativa de estudantes desenvolve uma média de oito horas diárias de atividades laborais para ter sua renda própria, que é mínima. Vivem ou trabalham na área rural, executando tarefas braçais, ocupações ligadas à agropecuária ou a serviços domésticos. Por essa razão, devido ao cansaço e ao sono, os estudantes faltam muito às aulas.

Em sala de aula, por meio do DR e das NC, a PP percebeu que as interações se constroem por intermédio de conversas paralelas entre os discentes sobre o que fazem em comum durante o dia. Após sondagem inicial para a pesquisa-ação, verificou que os alunos despertam-se para temas como ordenha e cuidado com cavalos, vacas, bezerros, tarefas do lar, trilhas com motos, alta velocidade, festas, diversão, drogas, bebidas alcoólicas, sexualidade e expectativa de novo emprego, e não no que efetivamente a professora regente trabalha em sala de aula: memorização de classes gramaticais escritas no quadro-negro, leitura de algum texto ou atividade do livro didático. Tirar leite de vaca e ler livros são ações que, na lógica daqueles estudantes, pertencem à dura realidade enfrentada. Embora elas façam parte da rotina e estejam no nível da obrigatoriedade, se mantêm rejeitadas pelos alunos.

No conselho de classe, é constatado o óbvio: os alunos só executam as atividades propostas pelos professores dentro das quatro paredes de sala, caso haja algum tipo de benefício em nota. A nosso ver, há um distanciamento caracterizado entre o que é promovido e o que, de fato, os alunos querem estudar. Ou seja, uma distância entre práticas escolares e gêneros presentes em suas vidas cotidianas. Em casa, gostam de assistir à TV e em sala de aula, embora estejam presentes fisicamente, muitos não esboçam reação diante do que lhes é apresentado. As expectativas discentes e docente se mantêm destoantes na configuração da aula de língua portuguesa e ir à escola se mostra uma oportunidade discente de encontrar os amigos para conversar sobre seus temas de interesse e identificação.

Percebemos, a partir do Quadro 3, que os estudantes almejam textos mais próximos de sua realidade, que apresentem "a realidade lá fora" e se 
materializem através de diálogos, músicas, isto é, de múltiplos letramentos e de multimodalidade, e não apenas na escrita.

QUADRO 3 - Configuração das aulas de língua portuguesa

\begin{tabular}{|c|c|c|}
\hline Participantes & Como são & Como gostariam que fossem \\
\hline Ana Flor & Até mais ou menos. & Com mais filmes, vídeos e etc. Porque é mais legal. \\
\hline Ana Victória & Enjoativa e sem graça. & $\begin{array}{l}\text { Gostaria que falasse sobre coisa que acontece no } \\
\text { diaadia, coisa que chama nossa atenção. }\end{array}$ \\
\hline Cachoera & $\begin{array}{l}\text { Copia, faz atividade avaliativa, lê texto } \\
\text { literário. }\end{array}$ & $\begin{array}{l}\text { Gostaria de conversar, de ler um livro, dialogar } \\
\text { sobre a matéria. }\end{array}$ \\
\hline Capricho & - & - \\
\hline Chefe & Acho legal, porque copia e lê. & Que tivesse só leitura. \\
\hline Diamante & $\begin{array}{l}\text { Muitas vezes enjoativas, porque } \\
\text { fazemos praticamente as mesmas } \\
\text { coisas todos os dias. }\end{array}$ & $\begin{array}{l}\text { Que tivesse mais aulas diversificadas e } \\
\text { discutíssemos coisas do nosso cotidiano. }\end{array}$ \\
\hline Estrella & $\begin{array}{l}\text { Copio texto e atividades, e, às vezes, } \\
\text { leio. }\end{array}$ & $\begin{array}{l}\text { Gostaria que fosse mais diversificada, como com } \\
\text { mais diálogo e interação. }\end{array}$ \\
\hline Goku & $\begin{array}{l}\text { Não entendo quase nada, porque a } \\
\text { professora não para de "torrar" as } \\
\text { paciências. }\end{array}$ & $\begin{array}{l}\text { Ver filme/ter uma professora que gosta de } \\
\text { português. }\end{array}$ \\
\hline José & Copiamos demais. & $\begin{array}{l}\text { Trocar a professora por uma melhor, que nos } \\
\text { deixasse mais felizes. }\end{array}$ \\
\hline Maresia & $\begin{array}{l}\text { Muito ruim, porque a professora é } \\
\text { muito chata. }\end{array}$ & Relacionado ao mundo, coisas atuais. \\
\hline Margarida & Copio texto, faço atividades, leio. & $\begin{array}{l}\text { Gostaria de ler mais, conversar sobre algo } \\
\text { importante, ter um dia de aula com vídeo. }\end{array}$ \\
\hline Mocher & $\begin{array}{l}\text { Muito ruim, porque a professora é } \\
\text { muito chata. }\end{array}$ & Relacionada a coisas do mundo atual. \\
\hline Omikami & São boas. & Com leitura e falar sobre elas, filmes, textos. \\
\hline Pedro & $\begin{array}{l}\text { A professora fica "torrando" a } \\
\text { paciência. }\end{array}$ & Ter uma professora que ensina melhor. \\
\hline Red Bull & Muito ruim. & Com a realidade lá fora, como convivemos. \\
\hline Tici & - & - \\
\hline Violeta & Chata. Às vezes são boas e outras não. & $\begin{array}{l}\text { Com mais filmes e diversão. Porque tem que ter } \\
\text { coisa diferente. }\end{array}$ \\
\hline Zika & $\begin{array}{l}\text { Escrevemos muito, algumas são } \\
\text { chatas. }\end{array}$ & $\begin{array}{l}\text { Gostaria que fosse mais animada, que passasse } \\
\text { mais filmes nas aulas. }\end{array}$ \\
\hline
\end{tabular}

Enquanto estão enfileirados, proibidos de usar o celular, a indisciplina justificada pelos professores em conselho de classe se traduz na oportunidade de vida e de expressão que os alunos têm fora da escola. Paira no ar o sonho 
comum de ter um bom emprego para ter dinheiro e comprar um bom carro equipado com som potente, ao mesmo tempo em que há a fuga da prática do copiar do quadro-negro. Esse exemplo nos leva a ecoar os pensamentos de Sibilia (2012) a respeito da falta de atratividade da aula de língua portuguesa no ensino médio, vista como algo chato e um calvário cotidiano a obrigação de frequentá-la.

QUADRO 4 - (Des)motivação em relação às aulas de língua portuguesa

\begin{tabular}{|c|c|c|c|}
\hline Participantes & Motivação para ir à escola & $\begin{array}{c}\text { O que mais gosta } \\
\text { nas aulas de língua } \\
\text { portuguesa }\end{array}$ & $\begin{array}{l}\text { O que menos gosta nas } \\
\text { aulas de língua portuguesa }\end{array}$ \\
\hline Ana Flor & $\begin{array}{l}\text { Conversar com os amigos e } \\
\text { aprender com as aulas. }\end{array}$ & $\begin{array}{l}\text { Aprender textos, poemas } \\
\text { etc. }\end{array}$ & De escrever. \\
\hline Ana Victória & $\begin{array}{l}\text { Desejo de ser alguém na } \\
\text { vida. }\end{array}$ & Ler e escrever. & Apresentar trabalho. \\
\hline Cachoera & Ter um futuro melhor. & De texto. & Copiar. \\
\hline Capricho & $\begin{array}{l}\text { Conversar, distrair e } \\
\text { aprender. }\end{array}$ & - & - \\
\hline Chefe & Fazer bagunça e ver as gatas. & Ler e escrever. & $\begin{array}{l}\text { Quando a professora me } \\
\text { enche a paciência. }\end{array}$ \\
\hline Diamante & $\begin{array}{l}\text { Ser independente e alguém } \\
\text { respeitado na sociedade. }\end{array}$ & $\begin{array}{l}\text { Copiar e dialogar sobre a } \\
\text { matéria. }\end{array}$ & Apresentar trabalho. \\
\hline Estrella & Ter um futuro promissor. & Ler. & Copiar matéria do quadro. \\
\hline Goku & Minha mãe "mandar" lanche. & Filmes e músicas. & Da professora loira. \\
\hline José & Ver os amigos. & Ver filmes. & Da professora loira. \\
\hline Maresia & $\begin{array}{l}\text { Conseguir um emprego } \\
\text { melhor. }\end{array}$ & $\begin{array}{l}\text { Ler e responder às } \\
\text { atividades. }\end{array}$ & De fazer trabalho em casa. \\
\hline Margarida & $\begin{array}{l}\text { Ser alguém na vida, fazer } \\
\text { uma faculdade. }\end{array}$ & Ler livros. & Copiar. \\
\hline Mocher & Ter um futuro melhor. & $\begin{array}{l}\text { Responder atividades } \\
\text { e ler. }\end{array}$ & Fazer trabalho em casa. \\
\hline Omikami & $\begin{array}{l}\text { Formar em um "ramo" que } \\
\text { goste. }\end{array}$ & $\begin{array}{l}\text { Texto, leitura, diálogo } \\
\text { sobre o que lemos e } \\
\text { filmes. }\end{array}$ & Muitas atividades. \\
\hline Pedro & Lanchar. & Música. & Copiar e vir para a escola. \\
\hline Red Bull & $\begin{array}{l}\text { Meu pai e minha mãe, para } \\
\text { ser alguém na vida. }\end{array}$ & Leitura. & Escrever. \\
\hline Tici & $\begin{array}{l}\text { Aprender mais, conversar } \\
\text { com os amigos. }\end{array}$ & - & - \\
\hline Violeta & $\begin{array}{l}\text { Para aprender, ver os amigos } \\
\text { e me divertir. }\end{array}$ & Ler e assistir a filmes. & Copiar muita coisa. \\
\hline Zika & A namorada e a mãe. & As explicações. & $\begin{array}{l}\text { De fazer atividade de escola, } \\
\text { ler e escrever. }\end{array}$ \\
\hline
\end{tabular}


Ir à escola para "ser alguém na vida" salta aos nossos olhos por se remeter a um discurso contido no questionário e também reproduzido constantemente pelos responsáveis dos discentes em reuniões escolares. "Ser alguém na vida", para os alunos, equivale a ter um futuro promissor, bom emprego, aprendizagem, altos salários, reconhecimento social, ascensão garantida a partir da responsabilidade particular para com a escola. Como constatado no estudo de Souza, Corti e Mendonça (2012, p. 35, grifos das autoras), mesmo lendo, escrevendo e falando, é comum decretarem à escola o contexto em que "o estudante tem de aprender a ler e a escrever para 'ser alguém na vida"'.

Em sala, grande parte dos alunos não demonstra preocupação em ir além do que lhe é repassado. Parece estar ali porque é uma norma social e, assim, é obrigada a permanecer e a cumprir o ritual. Alguns jovens não demonstram preocupação com a formação ética, crítica e autônoma, porque também são partícipes de uma educação alienada, reproduzida, sem problematizações ou reflexão sobre si e o/s outro/s sobre as próprias vivências (GEE, 2015).

Diante de tal cenário, compreender as políticas de ensino da língua torna-se relevante para problematizar o que se efetiva na prática. No que tange às orientações para o contexto de ensino médio, após o novo perfil definido na Lei de Diretrizes e Bases da Educação Nacional, LDBEN (BRASIL, 1996) referente à obrigatoriedade e gratuidade desse nível, são instituídas, entre outros documentos que regulamentam as práticas curriculares, as Diretrizes Curriculares Nacionais para o Ensino Médio, DCNEM (BRASIL, 1998), os Parâmetros Curriculares Nacionais para o Ensino Médio, PCNEM (BRASIL, 1999), os PCN+ (BRASIL, 2002), as Orientações Curriculares para o Ensino Médio, Ocem (BRASIL, 2006) e, especificamente no estado de Goiás, o Currículo de Referência (GOIÁS, 2012). Tais documentos trazem reflexões didáticas pertinentes direcionadas ao ensino/aprendizagem de língua portuguesa.

Tais documentos realçam, do ponto de vista pedagógico, a relação entre mundo do trabalho e prática social discente, com vistas ao exercício da cidadania, da profissão e dos estudos. Do ponto de vista linguístico, veiculam o caráter interdisciplinar da língua portuguesa amalgamada às situações sociais de uso (SOUZA; CORTI; MENDONÇA, 2012). Cabe ressaltar que, desde 1998, com as DCNEM, é concedida especial atenção à relação entre língua e práticas sociais, uma vez que, em qualquer disciplina, concretizamos 
ações de leitura, escrita e oralidade. Dessa forma, todo professor, e não apenas o de língua portuguesa, deve ter a capacidade de ampliar nos alunos o aspecto da linguagem por meio de textos (PIRES-SANTOS, 2015). Prescrevem os PCN+:

o ensino de Língua Portuguesa, hoje, busca desenvolver no aluno seu potencial crítico, sua percepção das múltiplas possibilidades de expressão linguística, sua capacitação como leitor efetivo dos mais diversos textos representativos de nossa cultura. Para além da memorização mecânica de regras gramaticais ou das características de determinado movimento literário, o aluno deve ter meios para ampliar e articular conhecimentos e competências que possam ser mobilizadas nas inúmeras situações de uso da língua com que se depara, na família, entre amigos, na escola, no mundo do trabalho (BRASIL, 2002, p. 55).

As diretrizes para o ensino de linguagem ampliam as possibilidades com as Ocem, para as quais "as ações realizadas na disciplina de Língua Portuguesa, no contexto do ensino médio, devem propiciar ao aluno o refinamento de habilidades de leitura e de escrita, de fala e de escuta" (BRASIL, 2006, p. 18). O documento em questão concebe o texto "como uma totalidade que só alcança esse status por um trabalho conjunto de construção de sentidos, no qual se engajam produtor e receptor" sob um enquadre de gêneros discursivos (BRASIL, 2006, p. 21).

As Ocem apostam nas trajetórias e nos letramentos sociais dos estudantes inseridos em sua comunidade e nas esferas sociais de participação. É por este caminho que o ensino da língua deve se pautar: pela realidade, perfil e demanda discente, em perspectiva localizada e, ao mesmo tempo, globalizada das experiências, para que se efetive a construção significativa do conhecimento. Para isso, "a escola que se pretende efetivamente inclusiva e aberta à diversidade não pode ater-se ao letramento da letra, mas deve, isso sim, abrir-se para os múltiplos letramentos" (BRASIL, 2006, p. 29).

Diante dessas considerações, é possível depreender que as Ocem, com menção literal do termo, defendem práticas de letramentos que não sejam baseadas na concepção tradicionalista de ensino-aprendizagem de língua, supervalorizadora do domínio do código escrito. À proporção que a escola trabalha com a língua/linguagem, faz-se necessário abrir espaços para reflexão sobre aspectos linguísticos, textuais, discursivos e sociopragmáticos. Defendem, ainda, uma perspectiva reflexiva ao enfatizar "a formação 
humanística e crítica do aluno, que o estimulem à reflexão sobre o mundo, os indivíduos e suas histórias, sua singularidade e identidade" (BRASIL, 2006, p. 33).

No estado de Goiás, outro importante documento é o Currículo de Referência de Língua Portuguesa ${ }^{7}$ que está organizado a partir de gêneros discursivos, e disposto para cada bimestre e série. Relacionando os eixos temáticos às expectativas de aprendizagem e aos conteúdos bimestrais, $\mathrm{o}$ enfoque ao uso da linguagem no documento está organizado em torno de gêneros com ênfase em práticas de oralidade (produção e compreensão oral), de leitura, de escrita e de reflexão sobre língua/linguagem. Embora flexível às demandas, na prática se consolida como uma espécie de cartilha de planejamento docente, como se para o trabalho com gêneros não fosse imprescindível a contextualização e a adaptação de textos. Tecemos a mesma crítica ao documento em se tratando da proposta de determinados gêneros para cada série, o que de certa forma incide equivocadamente numa prática homogeneizante e padronizada.

Considerando que a vida diária está permeada pelos gêneros, a pluralidade de sua adesão no ensino de línguas é salutar quando temos em mente a contextualização e seu funcionamento na vivência cotidiana dos estudantes. Optar exclusivamente por definir, conceituar e estruturar o gênero, dentro de sua heterogeneidade constitutiva, equivale a criar fôrmas para engessar seu enquadre, quando, na realidade, seu aspecto plural efetivamente se dá de acordo com o contexto, ou seja, com a particularidade de aspectos enunciativos de sua ocorrência.

Nesse sentido, compreendemos a constituição dos gêneros numa proporção mais ampla em comparação com os letramentos, que também são múltiplos. Os letramentos seriam, pois, construídos nos gêneros.Se os gêneros fazem a mediação e integram as práticas às atividades de linguagem, a organização dos conteúdos curriculares da disciplina de língua portuguesa, a partir dos gêneros, deveria demonstrar a preocupação em transformar o ensino em sala de aula em contextos concretos de práticas sociais da linguagem, sobretudo da escrita.

\footnotetext{
${ }^{7}$ Disponível em: < http://www.seduc.go.gov.br/imprensa/documentos/arquivos $/$ Curr $\% \mathrm{C}$ 3\%ADculo $\% 20$ Refer $\%$ C3\%AAncia/Curr $\%$ C 3\%ADculo $\% 20$ Refer $\%$ C $3 \%$ AAncia $\% 20 \mathrm{da}$ $\% 20$ Rede $\% 20$ Estadual $\% 20$ de $\% 20$ Educa $\%$ C3\%A7\%C3\%A3o $\% 20$ de $\% 20$ Goi $\%$ C3 $\%$ A 1 s!. pdf>. Acesso em: 26 set. 2017.
} 
Defendemos na ação implementada a concepção de ensinoaprendizagem de língua portuguesa orientada pelos letramentos, adotando os conteúdos propostos no Currículo de Referência, que prescreve o gênero, exige que o docente ultrapasse o que está descrito no documento, e parta das práticas sociais e das expectativas dos estudantes. O gênero não deve ser utilizado em sala apenas para atividades de interpretação, para uma posterior utilização nas práticas sociais, haja vista que "é a prática social que viabiliza a exploração do gênero, e não o contrário" (KLEIMAN, 2006, p. 33).

Relacionar as aulas de língua portuguesa às esferas e aos gêneros da vida cotidiana dos estudantes é ação fundamental para a promoção dos letramentos sociais e para a atratividade no ensino. Se o (des)interesse pelas aulas está associado às estratégias didáticas, temas escolhidos e metodologias adotados nas práticas pedagógicas, é preciso reflexão docente para que, conforme Hamilton e Barton (1999), as práticas de letramento vivenciadas no cotidiano não sejam banalizadas ou marginalizadas, mas acolhidas.

\subsection{O ensino/aprendizagem de língua portuguesa: entre letramento e letramentos}

A famosa frase de Paulo Freire (1989, p. 9) de que a "leitura do mundo precede a leitura da palavra" ilustra nossa adesão à perspectiva social e crítica dos letramentos (STREET, 2014). Está vinculada às considerações de Rojo (2009, p. 98), para quem o termo corresponde a uma perspectiva não individual, mas "sociológica, antropológica e sociocultural", "aos usos e práticas sociais de linguagem que envolvem a escrita de uma ou de outra maneira, sejam eles valorizados ou não valorizados, locais ou globais, recobrindo contextos sociais diversos". Nesse sentido, temos letramentos numa forma pluralizada, buscando desestabilizar a supremacia pedagógica do letramento escolar dominante (o da letra), ao mesmo tempo em que afirmamos sua natureza política, não neutra, intencional, ideológica e encaixada na cultura de uma sociedade envolta por relações de poder.

Nas palavras de Street (2014, p. 31, grifos do autor) "as pessoas não são 'tábuas rasas' à espera da marca inaugural do letramento, como tantas campanhas parecem supor". Assim, é importante reconhecermos que cada pessoa se inscreve em culturas locais, múltiplas, consoante práticas cotidianas e situadas, constituídas em diferentes agências, tais como família, igreja, escola etc. Aderir a essa nova perspectiva significa trilhar 
outras possibilidades didáticas para o ensino/aprendizagem de língua portuguesa, ação didática que requer a compreensão de que os letramentos se tornam "espaços socioculturais de construção da vida social ou, mais especificamente, de quem somos" (MOITA LOPES, 2013, p. 236), como contextos de construção de identidades. O foco passa a ser, portanto, o sujeito social com suas interpretações e negociações de sentido.

A concepção de letramentos na qual subsidiamos nossas análises não vê a oralidade e a escrita como dimensões polarizadas, mas sempre interligadas (STREET, 2014). Aspectos técnicos e artefatos culturais contidos nos letramentos não podem se dividir. Como Rojo (2009, p. 106107) salienta, eles são múltiplos: "diferenciados, cotidianos e institucionais, valorizados e não valorizados, locais, globais e universais, vernaculares e autônomos, sempre em contato e em conflito". Nesse sentido, há que se refletir sobre o que se rejeita e o que constantemente se prioriza na escola, uma vez que temos cidadãos heterogêneos em meio a práticas educativas, construindo diferentes identidades, porque também possuem propósitos diferenciados para com a aprendizagem de língua portuguesa.

Um fato que nos chamou a atenção em sala de aula aconteceu com o aluno Teixeira, quando a professora, incomodada, afirma para toda a sala que ele não conseguiu acertar nenhuma das cinco questões objetivas de interpretação. Em conversa informal, o aluno disse que não se importava, pois sabia que seria reprovado, e caso isso acontecesse, não estudaria mais. Disse não se importar com isso, mesmo com os olhos cheios de lágrimas. Teixeira, um garoto calmo em sala, que demonstrava ansiedade durante a realização de atividades devido ao sentimento de incapacidade, perguntava sempre aos colegas sobre seus acertos nas atividades.

[01] Ah, aquilo ali [a situação de correção oral ocorrida] para mim foi... deu vontade de pegar tudo e ir embora (semblante de tristeza). Eu pensei assim: "será que eu vou ter que ir embora?". E até hoje eu não peguei meu boletim, porque eu tenho certeza que em Português eu estou com nota vermelha. (Teixeira - NC)

Temos aí o retrato de um estudante frustrado com a exclusividade de sucesso cobrada pela escola na figura da professora de língua portuguesa. $\mathrm{O}$ fato é que, para além da relevância do acesso à variedade culta do idioma, cujo ensino também é papel da escola, percebemos a não inserção desse aluno à prática estabelecida, legitimada e fortalecida no contexto educacional, ao 
letramento exclusivamente escolar, o qual, nesse caso, segregou seu interesse, apagou suas identidades.

[02] [Eu não gosto, de jeito nenhum,] de ler [em voz alta], tipo assim: se o professor mandar eu ler, acho ruim. Já fui mandado para fora por causa de ler. A minha assinatura na secretaria é tudo por causa de ler, porque eu não gosto de ler em voz alta. [...] Mas de ler assim para mim não, é de boa!(Teixeira - NC)

As práticas de leitura e escrita promovidas em sala determinam o modo como os estudantes enxergam a disciplina de língua portuguesa. $\mathrm{O}$ desinteresse, às vezes, surge em razão de não conseguirem realizar tarefas propostas, as quais são muitas vezes impostas, ou mesmo demarcadas conforme as posições ocupadas nas relações de poder/saber travadas. Teixeira faz uma distinção do que significa ler para a professora e do que significa ler para ele, que, nesse caso, ler para si configura-se como prática mais segura. No decorrer das ações, esse jovem passou a se mostrar atento às discussões dos textos trabalhados em sala, talvez por se ajustarem mais às suas práticas reais, vividas fora de sala.

A proposta de ação orientada nos letramentos e fundamentada metodologicamente nos gêneros discursivos pautou-se em abordagens como as de Souza, Corti e Mendonça (2012) direcionadas ao ensino médio. Partiu do reconhecimento de que os alunos já participam do mundo letrado e, com isso, identificou as diferentes maneiras dessa ocorrência, ou seja, do que os alunos são e fazem. O levantamento realizado pela PP possibilitou a construção de uma sequência didática flexível, com aulas ministradas abarcando textos e debates vinculados à realidade dos estudantes. Foi projetada com resultados coerentes com as metas e ações idealizadas (GEE, 2015). O enfoque voltou-se às práticas de leitura, escrita e oralidade, com apreciações e discussões de textos multimodais que faziam sentido à vida discente.

A Figura 1, com base em Kleiman, Ceniceros e Tinoco (2013), em cumprimento às expectativas institucionais do conteúdo programático e em conexão com as práticas socioculturais vivenciadas e desejadas pelos estudantes, sintetiza as atividades realizadas ao longo de 17 aulas. $\mathrm{O}$ desenvolvimento das ações culminou na confecção de um jornal mural produzido pelos estudantes com escritas sobre coisas que lhes incomodavam na comunidade de que participavam. 
FIGURA 1 -Síntese das atividades realizadas

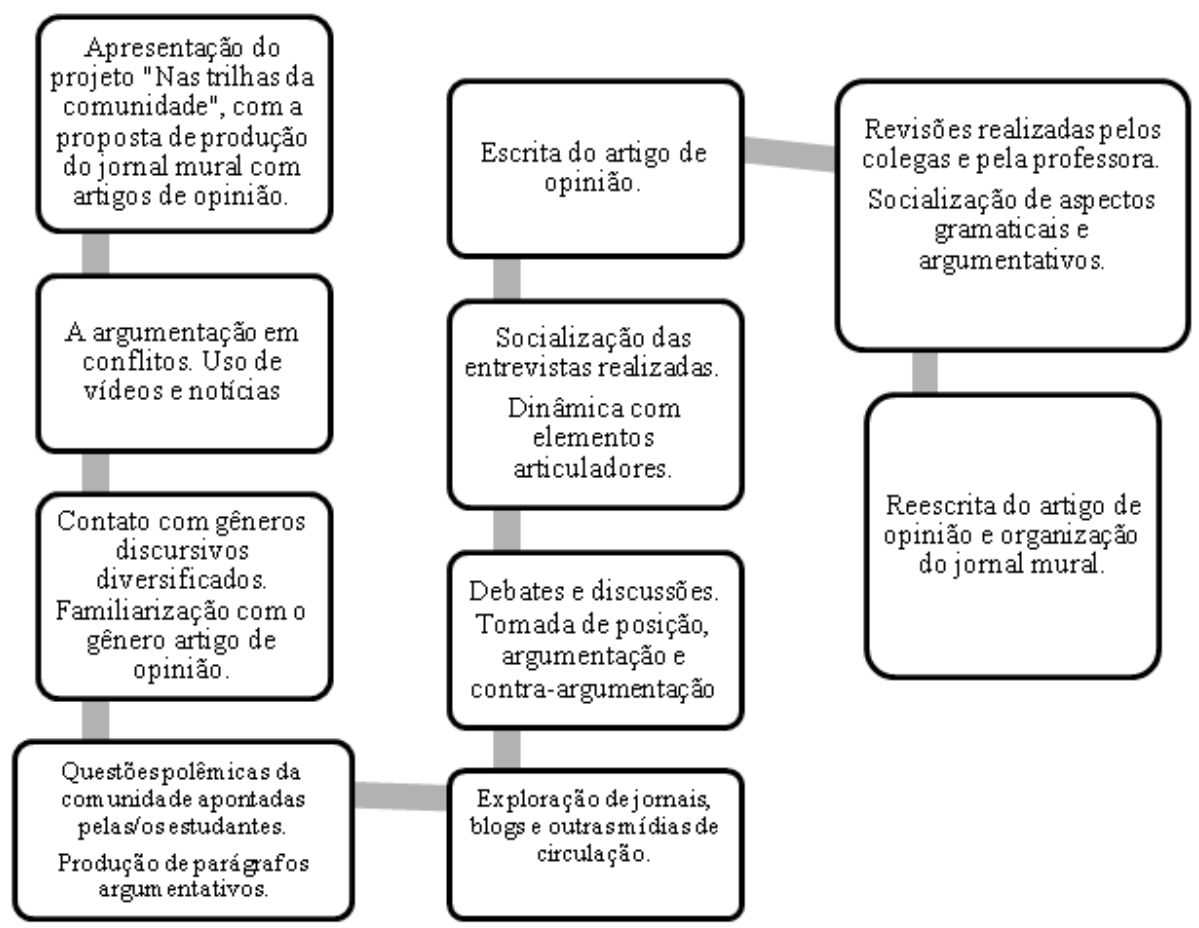

Fonte: elaborado pelos autores com base em Kleiman, Ceniceros e Tinoco (2013).

A perspectiva intergêneros se instalou no decorrer da flexibilidade de ação permitida pela sequência didática. Como estratégias metodológicas, a PP buscou inserir os estudantes como agentes das práticas de aprendizagem efetivada, demonstrando a importância da autonomia e da escuta sensível. Os alunos não "recebiam" os conteúdos programáticos, conceitos e arquitetura do que seria trabalhado, antes definiam em conjunto com a PP o que estudar. Participavam, seguindo a recomendação de Gomes (2013), da seleção dos textos para a aula. A aula cópia e ensaio, cujas ações eram verticalizadas pelo professor, deu lugar ao papel protagonista discente, à promoção de vozes. A língua portuguesa se contextualizou por essas brechas, cumprindo a determinação de documentos curriculares (BRASIL, 1999, 2002, 2006), que defendem aulas subsidiadas por texto/contexto, passando a fazer sentido de análise em vida. 
Os textos sugeridos versavam as temáticas cidadãs direcionadas especificamente para a saúde na comunidade, para o meio ambiente, evidenciando as queimadas no lixão próximo à cidade, a degradação do rio de Olhos D’Água, os espaços para a diversão jovem, como a construção de lugar apropriado para festas com som automotivo, e as questões escolares, como a proibição do uso do celular em sala de aula e a violência sexual na comunidade. Percebemos que os alunos se sentiam mais instigados a participar e a produzir quando se identificavam com tais temáticas abordadas, o que, nas recomendações de Gee (2015), significa dar vasão à aprendizagem contextualizada (situated meaning).

Ensinar língua portuguesa orientada pelos letramentos implica, ao passo que trabalhamos com gêneros discursivos, induzir suas caracterizações, partindo de textos e temas reconhecidos pelo grupo social. Os diferentes gêneros discursivos propostos, publicados em diferentes suportes e mídias, permitiram análises discentes sem preocupações voltadas às características estruturais. Com a pluralidade de gêneros na disciplina de língua portuguesa para possibilitar múltiplos letramentos (BRASIL, 2006), a produção e recepção de diferentes gêneros discursivos, longe de fins burocráticos e escolarizados, se incorporaram ao grau de significância e identificação dentro de contextos e enunciações que faziam sentido à vida do públicoalvo. Dessa forma, o desenvolvimento de conceitos, análises e produções com finalidade social e propósito comunicativo se instalavam espontânea e significativamente na prática de estudo da língua produzido em interação.

Enquanto avaliações de desempenho impulsionavam o fortalecimento social e institucional de que os estudantes participantes não conseguiam aprender os conteúdos normativos da língua e não conseguiam alcançar as expectativas de aprendizagem do Currículo de Referência, nossa principal tarefa era de que eles se reconhecessem naquele espaço por meio de quem eram, do que faziam, das práticas letradas de que participavam. Não configurava nossa intenção enfatizar limitações, demarcar incapacidades e evidenciar o que não conseguiam fazer. A postura baseada na abordagem de Hanks (2008, p. 95), a saber, de que nem "o gênero nem o texto isolado podem ser vistos como um produto acabado em si, mas permanecem parciais e transicionais", abriu espaço para tornarem legítimas as práticas que os alunos traziam para escola, para, sobre elas, refletirem e analisarem o fator língua/linguagem. 
Em uma das aulas implementadas, cujo propósito era possibilitar a familiarização dos estudantes com jornais impressos de circulação na região, foram visíveis o envolvimento e a curiosidade deles com a leitura. Isso ocorre porque, segundo Gee (2015), o letramento aumenta tipos de identidades e pressupõe identificações. Em grupos, folhearam, leram e discutiram sobre os diversos gêneros que encontraram e os assuntos abordados. Com postura ativa, identificaram o artigo de opinião no jornal, debateram o assunto abordado e as características do texto.

Tendo em vista os modos de vida global e tecnológico, os multiletramentos também configuraram a proposta por se direcionarem a dois tipos importantes de ação: "a multiplicidade cultural e a multiplicidade semiótica de constituição dos textos por meio dos quais ela se informa e se comunica" (ROJO, 2012, p. 13). As aulas ministradas foram construídas a partir de textos multimodais com mobilização semiótica presentes no cotidiano dos alunos, configurados na projeção de vídeos on-line, em canais de internet, entre outros suportes tecnológicos. Trabalhar na perspectiva de múltiplos letramentos possibilitou o desenvolvimento de práticas que estimularam a variedade de percepção sobre questões tratadas nos textos e a extrapolação de vozes culturais argumentando em sentido. Possibilitou, ainda, o exame sobre as semioses e sobre as multimodalidades linguísticas presentes em diferentes textos e gêneros. Toda essa mistura preocupada com aspectos da enunciação, inclusive, se vincula às orientações presentes em documentos oficiais para o ensino/aprendizagem de língua portuguesa, conforme discutimos.

Concebendo a intervenção como um evento de letramento em aulas de língua portuguesa, as perspectivas intercultural, crítica e multiletrada também fizeram parte da abordagem da PP sob a prerrogativa de Rojo e Moita Lopes (2004), que acenam para o sentido que os textos podem tomar no mundo social. Dessa forma, problematização e transgressão do posto se caracterizavam como tentativas de legitimação linguística e cidadã diante de tantas políticas educacionais de apagamento cultural das pessoas e de sua diversidade. A postura didática decolonial da PP surtiu como novidade e fez sentido para a vida dos estudantes. Logo, promoveu-se oportunidade de falar, ler, escrever e ouvir sobre e na língua portuguesa brasileira, refletir sobre processos identitários, e não mais se cunhou o propósito de nota e avaliação. 
$\mathrm{Na}$ efetivação da proposta, as interações permitiam aos alunos posicionamentos, argumentação, questionamentos, alteridade para se colocar no lugar do outro e reflexão crítica sobre ideologias e relações de poder em sociedade.

[03] O que conversamos lá dentro [de sala de aula] é o que acontece no dia a dia, no cotidiano. Então a gente levou um pouco do que vive, porque a gente não leva, né... a gente estuda só aquilo mesmo, segue regras. Então foi bom pegar o que está de fora e estudar lá dentro. Fez sentido. (Estrela - ES).

Leitura, produção e interpretação de textos locais funcionaram como uma espécie de emancipação e conhecimento da realidade, das vivências. $\mathrm{O}$ uso da oralidade resgatou a importância de cada aluno presente nas discussões em sala de aula.

[04] Nós estamos tendo aulas diferentes, vídeos, a gente está dialogando mais, tendo mais conhecimento com as coisas. Tem mais participação, discutindo polêmicas da nossa comunidade. [...] Está sendo muito polêmico. A gente, tipo assim... essas discussões é algo que a gente vive. [...] Porque é o que a gente está vivendo, a gente aprende argumentar mais na nossa vida. (Capricho - ES)

Como bem sabemos, a argumentação nos tempos atuais é um desafio. Em um artigo publicado na Revista Lingua Portuguesa, Pereira Junior (2013) afirma que a nossa compreensão sobre educação está relacionada com o que entendemos por argumentação. Se argumentar é posicionar-se e assumir identidades, tal prática é muito importante na construção de si e do/s outro/s, na legitimação dos saberes que trazemos e com os quais nos deparamos, na definição de acordos de respeito mútuo. Logo, é uma condição para a diminuição de preconceitos e de abertura à diversidade. Acreditamos que esse resgate tenha de partir exclusivamente da mobilização pedagógica em linguagem, em aulas de língua portuguesa, a partir da reflexão sobre gêneros orais, escritos e visuais.

[05] O que eu mais gostei é que teve muita leitura e a gente dialogou bastante, e é o que eu gosto bastante, não gosto muito quando o professor fica... só quer copiar, só fica virado, não quer conversar, tal... eu gosto muito quando a aula é assim, a gente discutiu bastante sobre o que está acontecendo, sobre nossa comunidade, sobre o que a gente estudou. (Ítalo - ES). 
Os textos trabalhados durante as aulas faziam alusões a questões polêmicas inscritas em acontecimentos contemporâneos dos alunos. À época, o estupro coletivo a uma garota no Rio de Janeiro foi tema de aula a partir de reportagens midiáticas, o que chamou a atenção dos alunos para debates e produção de cartazes sobre a violência e abuso sexual na própria comunidade. Desenvolver aulas de língua portuguesa na perspectiva de letramentos permitiu a constatação discente de que práticas de leitura, oralidade e escrita realizadas em outros contextos sociais podem ser reconhecidas como partes das ações letradas em sala.

[06] Do que eu estudei, a língua portuguesa era uma matéria chata, mas agora, do que a gente estudou, que usou o que está acontecendo, nossos assunto do dia a dia na língua portuguesa, já me despertou interesse, já vi que não é assim como eu pensava. Pra mim não tinha tanta importância assim... era só aprender a ler e escrever e pronto. (Diamante - ES)

Ao se referirem ao uso do que "está acontecendo", é possível inferir ainda que, nas posições ocupadas nas relações de poder, os estudantes não se viam em condições de discutir sobre o que conheciam, "o seu mundo". Tal posicionamento nos mostra que a perspectiva crítica dos letramentos abre caminhos para que as problemáticas que instigam os alunos sejam questionadas, reconhecendo, ainda, que existem outros letramentos, sejam eles dominantes ou marginalizados.

Considerando o pressuposto de Rojo (2009, p. 99) para quem as "práticas tão diferentes, em contextos tão diferenciados, são vistas como letramentos, embora diferentemente valorizadas e designando a seus participantes poderes também diversos", outra reflexão pedagógica relevante, dentro de um contexto ideológico marcado pela exclusividade escolar do letramento dominante, é a categorização sobre quem é "letrado". Além de definir posições de poder, tal questionamento configura a disciplina de língua portuguesa em sala de aula para ser pensada no cumprimento de conteúdos estabelecidos no bimestre, com função prioritária de obtenção de notas, com vistas a escamotear possibilidades de conexão com práticas sociais discentes vividas além dos muros da instituição.

Sobre isso alertamos para o fato de que não rechaçamos o letramento escolar promovido nos espaços educacionais. A propósito, é fulcral o papel docente de garantir o acesso discente ao letramento socialmente privilegiado, às variedades e modalidades de prestígio social, mas para isso não se deve ignorar a realidade vivida pelos alunos. A questão gira em torno da mediação 
pedagógica sensível à exclusividade desse letramento e o reconhecimento de outros que o aluno, por ventura, traz consigo; da efetiva junção pedagógica entre o evento e a prática de letramentos. Afinal, as práticas letradas escolares são também exigidas por órgãos superiores em exames de desempenho.

Sabemos que, historicamente, as questões de poder estão presentes no ensino/aprendizagem da língua portuguesa, que, por sua vez, foi inaugurado e reforçado pela exclusividade gramatical. Para Rezende (2015), o cenário das relações de poder tem implicações severas para o ensino/aprendizagem da língua ao longo da história. Em contextos formais, por exemplo, "os modelos de ensino e a correção escolar, sobretudo na escrita, são práticas maniqueístas de educação e de letramento escolar, constituindo estratégias poderosas de convencimento da incapacidade do brasileiro de aprender, inclusive sua própria língua" (REZENDE, 2015, p. 64, grifos da autora).

Em termos de letramentos, as implicações derivadas do binarismo entre Língua Portuguesa da escola e língua do estudante, conforme nossas interpretações neste estudo, apontam para o confronto discente entre conviver com o próprio grupo social, que se justifica como viver "coisas da vida", e o sobreviver em sala, que é tido como "coisas da escola". Com aulas de Língua Portuguesa engessadas, apartadas da cultura e das próprias demandas da comunidade, os participantes acabam tendo dificuldade de perceber a escrita e a leitura como atos sociais, letrados, porque culturalmente foram invisibilizados quando expostos às formas reduzidas, fraseadas e mecanicistas de se aprimorá-la. Em outras palavras, quase que literalmente, no contexto observado não falavam a língua da professora. Logo, não interagiam entre si.

[07] [A aula] Saiu de uma rotina. Parece que assim... quando a gente ouve assim do professor sobre uma aula diferente e tudo, mas sempre a gente já imagina uma atividade, uma coisa voltada, sei lá, muito fixada. As nossas foram muito diferente, por isso que eu gostei. (Ítalo - ES)

De acordo com Bagno (2015), o cenário que ora descrevemos limita as chances de se valer dos muitos recursos oferecidos pela língua, bem como desvaloriza a inclusão social, porque não se dá chances de perceber a diversidade da cultura brasileira ao estudar a língua. Conforme Rezende (2016, p. 25), num cenário plural, "em que convivem diferentes concepções e expectativas, diferentes maneiras de ver o mundo", não se pode apagar outros inúmeros modelos em prol da imposição de um único, "legítimo e autorizado". 
Diante disso, carecemos de investidas didáticas decoloniais por meio de rupturas paradigmáticas que deem vasão à complexidade constitutiva da língua que as pessoas em sala de aula usam e, especialmente, do papel que temos - professores e estudantes - concebido à educação. É necessária resistência contra um sistema que impõe um modelo unificado de ensino da língua, que historicamente se fortaleceu, por ironia do destino, em aulas de expressão sem a presença da oralidade (BRASIL, 1999), ao mesmo tempo em que compartimentaliza a percepção sobre linguagem por meio da distribuição de eixos escolares, como gramática, literatura e redação (PCNEM).

É igualmente relevante, do ponto de vista pedagógico, pensar na passividade discente diante da constante - e talvez quase inconsciente transmissão verticalizada do professor. Nessas condições, importa-nos rastrear o fluxo de comportamento linguístico mediado e interativo em detrimento da contínua prática de repetição do correto, do intocável, do reforço à ordem, à indiscutível regra, norma. É preciso, portanto, novos conhecimentos que, dotados de visão crítica, possibilitem abertura a novos paradigmas linguísticos e educacionais, de modo a libertar o professor de Língua Portuguesa do controle e da obediência social causada pela cultura monolíngue de ensino. Todas essas perspectivas homogeneizantes e depositadas ao aprender a língua portuguesa da escola são sequelas que podem ressoar em nossas ações futuras no mundo enquanto cidadãos sempre obedientes, conformados, dependentes e sujeitados.

Diferentemente do que constatamos, não deveria ser necessário participar de uma suposta cultura erudita para "ser alguém na vida", tampouco estar em sala de aula para ter uma vida melhor. Estamos falando de uma mudança de filosofia de trabalho: "a partir do que os estudantes são, do que conhecem e do que desejam para si próprios e para suas comunidades" (SOUZA; CORTI; MENDONÇA, 2012, p. 36). Estamos enfatizando uma transformação entre o trabalho docente sobre os estudantes para o trabalho com os estudantes. Afinal, para que haja identificação e motivação discente, conteúdo escolar e vida social precisam estar atrelados.

[08] Eu imaginava que [as aulas implementadas pela pesquisa-ação seriam] assim umas aulas de prova, tipo avaliar nós nas prova. Mas não foi isso, foi muito bom, foi com vídeo, com os artigos de opinião, foi fazer um jornal, que nós nunca tinha feito. Foi muito bom! (Teixeira $\mathrm{ES})$ 
Ao longo das aulas, percebemos a dificuldade discente na escrita alavancada pelo sentimento de incapacidade de produzir textos em norma culta. Após dias de trabalho de incentivo e de desmistificações desse saber, boa parte dos alunos se mostrou mais confiante nas atividades propostas. Sem negar a função da escola de propiciar o acesso dos estudantes a letramentos dominantes, a consideração e legitimação dos letramentos constituídos em outras agências sociais e culturais, trazidos pelos estudantes, por meio de práticas pedagógicas que lhes são significativas, sem imposições, contribuíram para a construção do letramento escolar. Não é uma questão de separar, mas de integrar letramentos. Ao reconhecer que os estudantes trazem letramentos, os quais merecem ser valorizados, estamos contribuindo para valorizar identidades. Longe da estratégia de instrumentalização e de mecanização linguística, da definição de conceitos e nomenclaturas, os processos de leitura e escrita se fizeram presentes na vida acontecendo em sala de aula e foram reconhecidos pelos estudantes.

Os alunos tiveram outra concepção de aula de língua portuguesa ao conhecer as finalidades do que vão produzir, para quem, qual mídia será utilizada para divulgação etc. Com isso, deixaram de ver a língua/linguagem como estando em um vácuo social:

[09] Igual ao jornal mesmo, que a gente fez, que a senhora [PP] passou para gente fazer, o que a gente escreveu foi uma coisa da nossa realidade, foi uma coisa que a gente vê ou já passou... não é uma coisa que a gente vai inventar, é uma coisa que a gente vive hoje e vai viver daqui a uns anos. (Anny - ES)

A partir das práticas letradas chegamos à produção de um jornal mural. Os textos produzidos, embora nem sempre típicos do cotidiano dos estudantes, foram assimilados a partir do contato com mídias e gêneros diversos relacionados às suas vivências. Com base em Bakhtin (1997), as atividades enfatizaram a composição de sentido de escritas, orientadas por gêneros discursivos, as quais puderam contribuir com a (des)construção de novas percepções discentes acerca da disciplina de língua portuguesa. Em Gee (2015), por fim, enfatizamos que proporcionar aos alunos múltiplas experiências em favor da compreensão sobre abstração e generalização, para que testem padrões e construam novas possibilidades para si, é fulcral em situações de ensino de línguas. Especialmente, se entendemos que nossa mente está a serviço do pensamento, ação e construção de significados para a linguagem escrita, oral e do mundo. 


\section{Considerações em trânsito}

Existia uma lacuna problemática entre o que era defendido nas práticas de letramento escolar e o que era relevante social e culturamente na vida dos jovens. O desinteresse, a desmotivação, o desestímulo dos estudantes nos levaram a perguntar: quem são eles? Onde estão? De onde vêm? Onde estudam? São jovens que trabalham o dia todo, em atividades rurais ou domésticas, e estudam à noite, em uma escola pública do interior de Goiás. No período de descanso, vão à aula, vão estudar, estão exaustos. Desejam "ser alguém na vida", ao mesmo tempo em que gostam de aventuras, adrenalinas, assistir à TV e conversar nas redes sociais.

Sem condená-los ou julgá-los, a proposta envolvendo letramentos e gêneros discursivos por meio de temas localizados, definidos e construídos pela agência dos estudantes, sob a coordenação da PP, vence até o cansaço. Ao se reconhecerem nos seus letramentos, os estudantes se sentem importantes e se interessam pelas práticas promovidas nas aulas. Pensar o ensino/aprendizagem de língua portuguesa na perspectiva que adotamos neste texto e tentamos construir na prática corresponde à verdadeira integração entre escola e comunidade.

A falta de abertura do sistema educacional para expectativas diferentes das solicitadas pelos órgãos superiores, bem como o currículo que comprime a possibilidade de intervenção prática docente, constituem-se desafios nessa empreitada. Foram necessárias resistências, omissões e muito "jogo de cintura”, para que a proposta fosse desenvolvida como planejada. Contudo, a construção da educação transformadora, da decolonização no ensino de língua portuguesa se resume no próprio fato de os estudantes ficarem na aula, apesar de suas condições físicas; de deixarem de copiar valentemente, de seguir as regras, normas, "pegar o que está fora e estudar lá dentro". As pessoas querem e precisam ver sentido no que elas fazem. Aliás, é preciso ter vida em tudo que se faz. Nesse sentido, os letramentos plurais superam a noção de letramento centrado na letra, no sistema de escrita alfabética e ampliam as possibilidades de se viver a língua, a vida. 


\section{Referências}

BAKHTIN, M. Estética da criação verbal. São Paulo: Martins Fontes, 1997.

BRASIL. Lei ñ 9.394, de 20 de dezembro de 1996. Estabelece as diretrizes e bases da educação nacional. Brasília, DF, 1996. Disponível em: < https://bit.ly/2KZISaB>. Acesso em: 15 out. 2017.

BRASIL. Resolução CEB, $n^{\circ} 3$, de 26 de junho de 1998. Institui as Diretrizes Curriculares Nacionais para o Ensino Médio. Brasília, DF, 1998. Disponível em: < https://bit. ly/2JK00D3>. Acesso em: 31 out. 2017.

BRASIL. Parâmetros Curriculares Nacionais: ensino médio. Parte II - Linguagens, códigos e suas tecnologias. Brasilia, DF: Ministério da Educação, 1999.

BRASIL. PCN+ ensino médio: orientações educacionais complementares aos Parâmetros Curriculares Nacionais - Linguagens, códigos e suas tecnologias. Brasília, DF: Ministério da Educação, 2002.

BRASIL. Orientações Curriculares para o ensino médio: linguagens, códigos e suas tecnologias. Brasília, DF: Ministério da Educação, 2006. v. 1.

DENZIN, N. K.; LINCOLN, Y. S. Introdução: a disciplina e a prática da pesquisa qualitativa. In: DENZIN, N. K.; LINCOLN, Y. S. (Ed.). Planejamento da pesquisa qualitativa: teorias e abordagens. Porto Alegre: Artmed, 2006. p. 15-42.

DOLZ, J.; NOVERRAZ, M.; SCHNEUWLY, B. Sequências didáticas para o oral e a escrita: apresentação de um procedimento. In: SCHNEUWLY, B; DOLZ, J. Gêneros orais e escritos na escola. Trad. Roxane Rojo e Glaís Sales Cordeiro. Campinas: Mercado de Letras, 2004. p. 95-128.

FLICK, U. Introducão à pesquisa qualitativa. Porto Alegre: Artmed, 2009.

FREIRE, P. Pedagogia do oprimido. Rio de Janeiro: Paz e Terra, 1987.

FREIRE, P. A importância do ato de ler: em três artigos que se completam. 23. ed. São Paulo: Cortez, 1989.

GEE, J. P. Literacy and education. New York: Routledge, 2015.

GOIÁS. Secretaria de Estado da Educação. Currículo Referência da Rede Estadual de Educação de Goiás. Versão experimental. Goiânia, 2012.

GOMES, J. J. O gênero grafite no ensino médio. In: BUNZEN, C.; MENDONÇA, M. (Org.). Múltiplas linguagens para o ensino médio. São Paulo: Parábola Editorial, 2013. p. 119-134.

HAMILTON, M.; BARTON, D. The texts of everyday life: public and private identities in vernacular literacy practices. Cadernos de Linguagem e Sociedade, Brasília, DF, v. 3, n. 2, p. 45-71, 1999. 
HANKS, W. F. Lingua como prática social: das relações entre língua, cultura e sociedade a partir de Bourdieu e Bakhtin. São Paulo: Cortez, 2008.

KLEIMAN, A. Leitura e prática social no desenvolvimento de competências no ensino médio. In: BUNZEN, C.; MENDONÇA, M. (Org.). Português no ensino médio e formação do professor. São Paulo: Parábola Editorial, 2006. p. 23-36.

KLEIMAN, A.; CENICEROS, R. C.; TINOCO, G. A. Projetos de letramento no ensino médio. In: BUNZEN, C.; MENDONÇA, M. (Org.). Múltiplas linguagenspara o ensino médio. São Paulo: Parábola Editorial, 2013. p. 69-83.

MAINARDES, C. Ensino de língua portuguesa é um fracasso: para o escritor Marcos Bagno, o ensino tradicional não leva em conta o uso brasileiro do português e adota práticas inúteis e irrelevantes. Revista Profissão Mestre, Curitiba, n. 188, p. 26-31, 2015.

MASCIA, M. A. A. O discurso de letramento e as relações de poder: por uma abordagem menos ilusória. Travessias, Cascavel, v. 3, n.3, p. 138-153, 2009.

MOITA LOPES, L. P. Gênero, sexualidade, raça em contextos de letramentos escolares. In: . Linguística Aplicada na modernidade recente. São Paulo: Parábola Editorial, 2013. p. 227-248.

PEREIRA JUNIOR, L. C. Educar é argumentar. Revista Lingua Portuguesa, São Paulo, ano 8, n. 88, p. 37-42, 2013.

PIRES-SANTOS, M. E. et al. "Vendo o que não se enxergava": condições epistemológicas para construção de conhecimento coletivo e reflexivo da língua(gem) em contexto escolar. DELTA, São Paulo, v. 31, p. 35-65, 2015.

REZENDE, T. F. Políticas de apagamento linguístico. In: BARROS, D. M.; SILVA, K. A.; CASSEB-GALVÃO, V. (Org.). O ensino em quatro atos: interculturalidade, tecnologia de informação, leitura e gramática. Campinas: Pontes Editores, 2015. p. 63-77.

REZENDE, T. F. Ensino intercultural de línguas. In: JORNADAS INTERNACIONALES: DESCOBRINDO CULTURAS EM LÍNGUA PORTUGUESA, II., 2016, Córdoba. Actas... Córdoba: Universidade Nacional de Córdoba, 2016. p. 24-32.

ROJO, R. Letramentos múltiplos, escola e inclusão social. São Paulo: Parábola Editorial, 2009.

ROJO, R. Pedagogia dos multiletramentos: diversidade cultural e de linguagens na escola. In: ROJO, R.; MOURA, E. (Org.). Multiletramentos na escola. São Paulo: Parábola Editorial, 2012. p. 11-31. 
ROJO, R.; MOITA LOPES, L. P. (Org.). Linguagens, códigos e suas tecnologias. In: BRASIL. Secretaria de Educação Básica do Ministério da Educação: Departamento de Políticas de Ensino Médio. Orientações curriculares do ensino médio. Brasília, DF: Ministério da Educação, 2004. p. 14-59.

SIBILIA, P. Redes on paredes: a escola em tempos de dispersão. Trad. Vera Ribeiro. Rio de Janeiro: Contraponto, 2012.

SOUZA, A. L. S.; CORTI, A. P.; MENDONÇA, M. Letramentos no ensino médio. São Paulo: Parábola Editorial, 2012.

STREET, B. V. Letramentos sociais: abordagens críticas do letramento no desenvolvimento, na etnografia e na educação. Trad. Marcos Bagno. São Paulo: Parábola, 2014.

TERRA, M. R. Letramento e letramentos: uma perspectiva sócio-cultural dos usos da escrita. DELTA, São Paulo, v. 29, n 1, p. 29-58, 2013.

THIOLLENT, M. Metodologia da pesquisa-ação. São Paulo: Cortez, 2005.

Data de submissão: 12/11/2017. Data de aprovação: 30/05/2018. 